\title{
A Study of Lean Burn Pre-chamber Concept in a Heavy Duty Engine
}

Author, co-author (Do NOT enter this information. It will be pulled from participant tab in

MyTechZone)

Affiliation((Do NOT enter this information. It will be pulled from participant tab in MyTechZone)

\begin{abstract}
Due to stringent emission standards, the demand for higher efficiency engines has been unprecedentedly high in recent years. Among several existing combustion modes, pre-chamber spark ignition (PCSI) emerges to be a potential candidate for high-efficiency engines. Research on the pre-chamber concept exhibit higher indicated efficiency through lean limit extension while maintaining the combustion stability. In this study, a unique pre-chamber geometry was tested in a single-cylinder heavy-duty engine at low load lean conditions. The geometry features a narrow throat, which was designed to be packaged inside a commercial diesel injector pocket. The pre-chamber was fueled with methane while the main chamber was supplied with an ethanol/air mixture. The 'avalanche activated combustion' or L.A.G. process was explored which relies on enriched pre-chamber combustion to generate radicals which, upon being discharged into the main combustion chamber, will trigger ignition sites distributed in the combustion chamber, thus achieving fast combustion. The ability of PCSI concept to enhance the lean limit with progressive enrichment in the pre-chamber was demonstrated. In addition, passive pre-chamber concept, where no additional fuel was injected into pre-chambers, was also explored and compared against the fueled pre-chamber experiments. The processed data features fast combustion rates with high combustion stability with the evident extension of the lean combustion limit. The engine-out emissions, measured by the exhaust gas analyzer, were reported together with the combustion data.
\end{abstract}

\section{INTRODUCTION}

In recent years, regulatory bodies have been striving to reduce carbon emissions, especially in the transportation sector, to counteract the global warming and the associated environmental challenges. Moreover, stricter regulations are either planned or already imposed to uplift the emission standards. Hence, the novel combustion concepts have been thoroughly researched for an increased engine efficiency and reduced pollutant discharge. By improving the efficiency of an engine, one can expect to lower the fuel consumption for a required energy output and thereby, can reduce $\mathrm{CO}_{2}$ emission.

One potential pathway to high efficiency engines is to move towards lean burn combustion concepts. Combustion with air-fuel ratios significantly higher than stoichiometry can improve the efficiency which can be effectively explained by the Otto cycle efficiency equation.

$$
\eta_{O t t o}=1-\frac{1}{C_{R}^{(\gamma-1)}}
$$

The efficiency increases with increasing compression ratio $\left(C_{R}\right)$ but friction losses and heat transfer losses will become more significant at higher compression ratios. On the other hand, increasing the excess air ratio $(\lambda)$ can improve the specific heat ratio $(\gamma)$ and thus can improve the efficiency of an engine. Moreover, the excess air will reduce the combustion bulk gas temperature which will reduce heat transfer losses further and diminish thermal NOx formation. One additional advantage of lean combustion is that the knock tendency is reduced due to lower bulk gas temperature. Thus the engine can be operated at advanced spark timing and could operate at higher compression ratios. It can be safely concluded that the aim of modern engine research is to achieve fast combustion at lean or diluted conditions.

However, igniting a lean air-fuel mixture has been a challenge for many years. As the air-fuel ratio approaches ignitability limit, the required ignition energy increases in an exponential manner, which raises the cost and complexity of ignition systems [1]. If stable and reliable ignition were not achieved, it would lead to poor utilization of the injected fuel leading to higher $\mathrm{HC}$ and CO emissions. Moreover, the ignition instability is one major culprit of high cycle-to-cycle variations and could lead to rough opera- 
tions of the engine. Thus, research focus on ignition energy development has been an area of interest for modern engine research for the past decades.

One way to alleviate ignition problems is to employ a prechamber, where the fuel is injected and partially burned followed by the products of combustion being issued into the main combustion chamber. The application of prechambers has been well established in stationary engines in the power generation sector. The pre-chamber is usually a small volume, accounting for a few percentage of the engine clearance volume. This chamber is communicated with the main combustion chamber via several nozzle holes. The pre-chamber can be either directly fueled (active pre-chamber) or unfueled (passive pre-chamber). To initiate combustion, a spark discharge event is triggered inside the pre-chamber which leads to a subsequent pressure rise in the pre-chamber.

The rising of pre-chamber pressure higher than that of the main chamber, causes the transfer of combustion products, which contains active radicals, through the nozzles into the main combustion chamber, in the form of hot turbulent jets. These pre-chamber jets will initiate multiple ignition sites along the surface of the jet and hence support a rather volumetric or distributed heat release inside the main chamber. Due to the multitude of ignition sites, pre-chamber combustion is able to burn lean air-fuel mixtures with a greater stability than conventional spark plug systems [2].

Due to efficiency improvements and higher ignition energy, pre-chamber combustion has been extensively studied in the past years. L.A.Gussak, one of the prominent researchers in this field, studied the behavior of pre-chamber jets in an engine. His concept is known as L.A.G process in Russian which is translated as 'Avalanche Activated Combustion' [3]. Gussak's idea is that the pre-chamber must be fuel-rich to generate active radicals which upon discharge into main chamber, will react with oxygen from lean main chamber charge, thus resulting in fast combustion rates. $\mathrm{He}$ proposed that using a low temperature torch or jet containing partially burned products were more advantageous in igniting lean mixtures instead of using a flame. He conducted several experiments to estabish the importance of chemically active species in the role of igniting lean main chamber charge.

Oppenheim et al. [4] also studied the underlying physics of pre-chamber jets in a combustion vessel and proposed it as one of the most promising technologies to control combustion inside the combustion chamber. In a similar setup, Yamaguchi et al.[5] explored the effect of pre-chamber nozzle or orifice diameter using optical diagnostics techniques. He deducted that the small nozzle diameter would lead to higher jet penetration lengths whereas the large nozzle diameter would lead to formation of a flame torch.

MAHLE Powertrain has conducted further studies on the pre-chamber concept. Attard et al. [6] proposed a Turbulent Jet Ignition (TJI) system to replace the spark plug in a four valve, pent roof engine, achieving an improvement of
$18 \%$ on the fuel consumption when compared to a conventional stoichiometric spark ignition mode. The efficiency improvement was coupled with single digit number of ppm in NOx emission, while featuring low values for unburned hydrocarbon (UHC) and carbon monoxide (CO) emissions [6]. The same group of researchers performed extensive optical studies on the main chamber combustion characteristics, measuring spatial distribution of important species such as $\mathrm{OH}$. Gentz et al. [7, 8] performed fundamental studies on TJI on a Rapid Compression Machine (RCM) to understand the behavior of liquid-fueled pre-chambers. The group characterized the pre-chamber jets by employing optical diagnostic techniques and discovered a unique turbulent flame structure.

In 2015, Shah et al. studied the effects of pre-chamber geometries based on an extended version of Gussak's experimental matrix. The experiments were performed on heavy duty as well as medium-speed engines and provided insight into the effect of pre-chamber geometry on combustion characteristics [9, 10, 11, 12]. The team confirmed the scalability of pre-chamber combustion and analyzed the engine performance with various pre-chamber and main chamber fueling ratios. The results further confirmed Gussak's recommendation of pre-chamber volume and nozzle area.

The main chamber combustion characteristics after the discharge of pre-chamber jets have been studied extensively and perhaps understood well. In recent studies, the emphasis shifted towards the physical phenomenon which occurs inside the pre-chamber during the compression stroke and events following the pre-chamber combustion. Fundamental studies have been conducted in combustion vessels using pre-chambers with optical access [13, 14, 15]. Such studies were performed under precisely controlled conditions, unlike engine experiments, and can provide explanation on the physical processes. There have been notable advancements in the zero-dimensional and one dimensional modeling as well. For instance, the 0-D turbulence and heat transfer model developed by Bardis et al. showed good correlation with the experimental data [14].

The CFD modelling has been extensively used to study the PCSI combustion as well. Majority of the CFD studies were targeted at resolving fluid dynamics inside the prechamber. The flow field inside the pre-chamber is governed by the internal geometry of the pre-chamber and thus the geometrical effects have been a focus area in recent years. For example, $\mathrm{Xu}$ et al. conducted 3D CFD study upon the flow behavior for different pre-chamber configurations [15]. Moreover, Thelen and Toulson carried out a CFD study based on the TJI Michigan design and they showed the importance of the spark plug location for a fast ignition [16]. Gholamisheeri et al. highlighted the influence of the throat area upon the flow behavior in the pre-chamber and presented a descriptive study of the pre-chamber flow field [17, 18].

Upon close observation on engine experiments, a distinctive trend can be noted where permanent or semipermanent modifications were imposed upon the engine 
cylinder head to accommodate the pre-chamber assemblies. A prevalent procedure noted was expanding the diesel injector or spark plug hole on the base engine. Increasing the opening areas in combustion chamber will reduce the strength of the engine cylinder head which might reduce the lifetime of an engine. Subsequently, it is of interest to the industry if the pre-chamber assemblies can be retrofitted on the engines with minimum or no modification to the cylinder head. In the latter case, the end-users can convert back to original configuration, if desired, without compromising the integrity of an engine. However, in avoiding modification to the engine, the design constraints imposed geometrical dimensions which could deteriorate flow characteristics in the pre-chamber such as a narrow throat diameter. In such a scenario, it is intriguing to examine the performance of such pre-chambers against those tuned for the best performance.

In this present work, the authors designed a pre-chamber assembly based on a single-cylinder research engine at KAUST. The pre-chamber design was adapted to the outside dimensions of the central diesel injector so that the complete assembly could be fitted into the injector pocket and thereby, avoided major engine modifications. The geometrical constraints led to an unavoidable narrow and long throat design. Experiments were performed on the prechamber at 1 bar intake pressure at various fueling rates and despite the narrow throat diameter, stable engine operation was achieved at lean conditions.

Due to the nature of the pre-chamber geometry, significant unburned hydrocarbons (UHC) emissions and some levels of NOx were observed. Subsequently, the indicated efficiency of the engine suffers due to poor utilization of the fuel energy. In order to assess the equivalence ratio inside the pre-chamber at the time of sparking, a conceptual model was employed to calculate mass transfer between pre-chamber and main chamber. In addition, the three-pressure-analysis was performed using GT-Power 1D model to estimate the discharge coefficients from the prechamber nozzles and hence, the trapped mass inside the pre-chamber can be determined. Detailed discussions can be found in subsequent sections.

\section{EXPERIMENTAL SETUP}

The experiments were performed on the single-cylinder research engine donated by Volvo Trucks (D13C500) which was modified into a research engine by MESA Engine Solutions. The baseline engine was a six-cylinder diesel engine which is converted into a single-cylinder test cell by deactivating five cylinders. For the pre-chamber experiments, the compression ratio of the engine was reduced to 11.5 by replacing the piston with a lower compression ratio to avoid auto-ignition or knock. The details about the experimental engine are presented in table 1 .

A new intake manifold with pockets for two port fuel injectors was constructed to allow manifold injection of fuel to main chamber. The intake air is taken from the lab air supply line at 45 bar pressure which is reduced to required
Table 1: Engine specifications

\begin{tabular}{|l|c|c|}
\hline Engine Model & \multicolumn{2}{|c|}{ D13C500 } \\
\hline Piston Shape & \multicolumn{2}{|c|}{ Bowl-in-piston } \\
\hline Valve Mechanism & \multicolumn{2}{|c|}{ Single Overhead Cam } \\
\hline Number of Valves & \multicolumn{2}{|c|}{ 2-intake 2-exhaust } \\
\hline Bore & 131 & $\mathrm{~mm}$ \\
\hline Stroke & 158 & $\mathrm{~mm}$ \\
\hline Connecting Rod Length & 255 & $\mathrm{~mm}$ \\
\hline Compression Ratio & 11.5 & {$[-]$} \\
\hline Displacement Volume & 2.1 & Liter \\
\hline Intake Valve Timing & $\begin{array}{c}\text { Open } \\
\text { Close }\end{array}$ & -330 CAD aTDC \\
\hline Exhaust Valve Timing & $\begin{array}{c}\text { Open } \\
\text { Close }\end{array}$ & $\begin{array}{c}\text { 180 CAD aTDC } \\
\text {-340 CAD aTDC }\end{array}$ \\
\hline
\end{tabular}

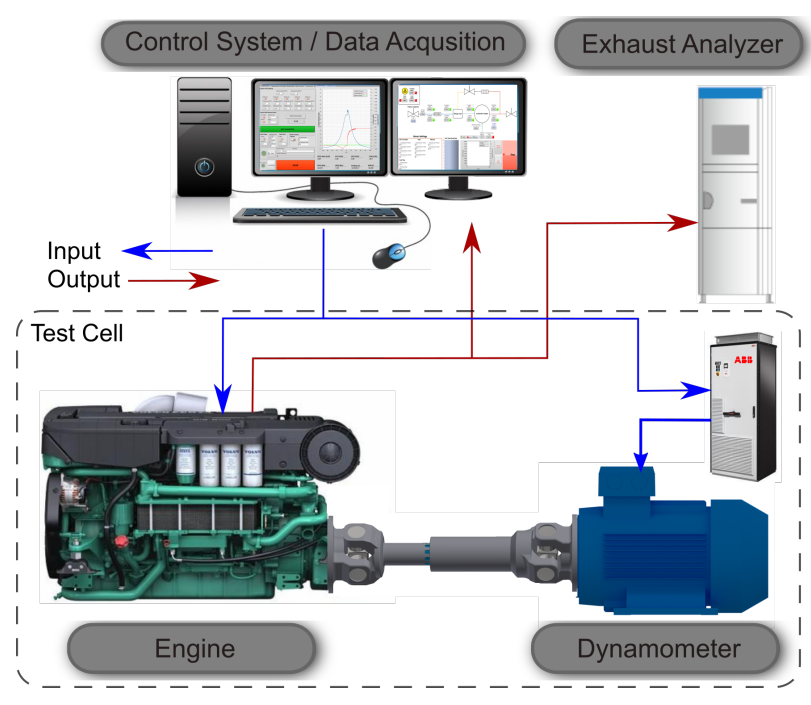

Fig. 1: Single cylinder Volvo testcell

intake pressure of 1 bar by means of a pressure regulator. The engine is driven by an ABB electrical motor, as shown in figure 1, which also acts as a dynamo-meter. A control/data-acquisition system drives the engine operation and collect measured data from the test cell. In addition, emissions are measured using an Horiba MEXA 1700 exhaust gas analyzer.

As described in the figure 2, the engine is fitted with two fuel systems. The main chamber fuel injection is performed by two solenoid-controlled port fuel injectors (3). Pre-chamber fueling is achieved by means of a solenoidoperated gas injector (8) installed upstream of the miniature check valve inside the pre-chamber adaptor. The volume flow rate to the pre-chamber is controlled via a thermal mass flow controller (9) from Brooks. Stable metering of pre-chamber fueling is achieved by assigning mass flow controller as master and the pre-chamber injector as slave. It means that only the mass flow controller is determining the amount of fuel flow and the pre-chamber injector operation has no effect on mass flow rate as long as the injector is opened for a sufficiently long duration. Such an arrangement provided stable mass flow. The gaseous fuel from pressurized cylinder is supplied to the mass flow controller via a filter (21) and a pressure damping vessel (12). 


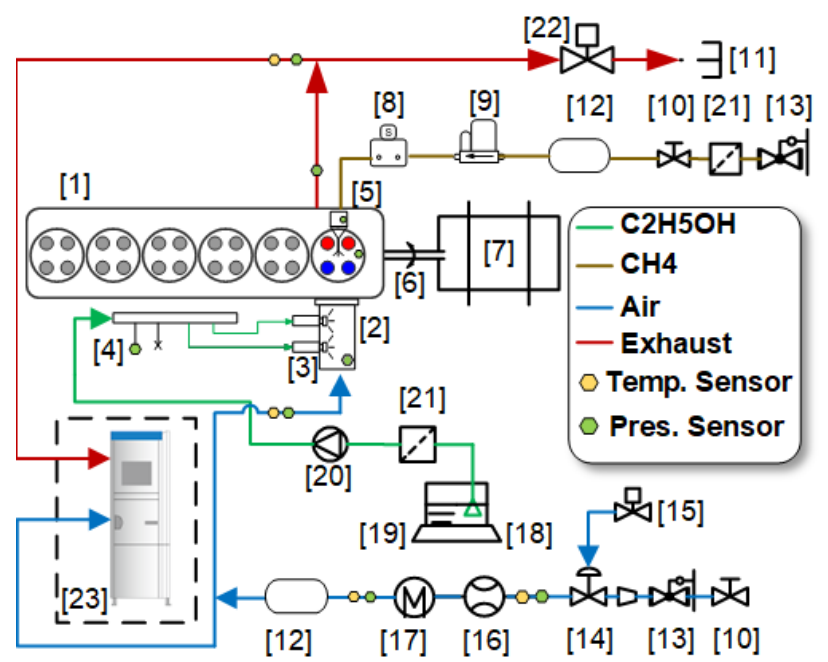

Fig. 2: Experimental setup:

1. Engine, 2. Intake, 3. PFI, 4. Rail, 5. Pre-chamber, 6. Cardan shaft, 7. Dynamometer, 8. Gas block injector, 9. Mass flow controller, 10. Valve, 11. Vent to atmosphere, 12. Damping vessel, 13. Pressure regulator, 14. Throttle Control Valve, 15. Pneumatic control valve, 16. Mass flow meter, 17. Air heater, 18. Fuel tank, 19. Fuel balance, 20. Fuel pump, 21. Fuel filter, 22. Exhaust Back Pressure Valve, 23. Horiba exhaust analyzer

An automotive port fuel system is employed for the main chamber fueling system. A submerged pump (20) transfers fuel from the tank to a low pressure rail and kept the fuel pressure constant at 4 bar. The common rail (4) supplied the fuel to the injectors. The amount of fuel flow from the tank is measured by a mass balance system (19). The engine intake is fitted with air heater (17) to maintain the constant air temperature. During the experiments the throttle valve (14) was keep in one position that provides around 1 bar inlet pressure.

\section{INSTRUMENTATION AND DATA ACQUISITION}

The engine test cell is operated by a LabVIEW fpga-based real-time embedded control system. The host PC transfers user-input control data to the NI-CompactRIO, where the latter controls the engine operations while acquiring various output signals from the engine simultaneously. The CompactRIO is fitted with NI C-Series modules, performing specific functions for control and data acquisition. A crank encoder is installed onto the engine crankshaft to provide crank angle positions with 0.2 CAD intervals. Piezoelectric pressure transducers are fitted inside the cylinder as well as the pre-chamber and their output is amplified using charge amplifiers which feeds the high-speed data acquisition module.

In addition, the intake and exhaust manifold pressures are also recorded at high-resolution using piezoresistive pressure transducers with built-in voltage amplifiers. Absolute pressure sensors are also fitted to engine lubricating oil circuit, intake and exhaust manifold. The flow rate of intake air is measured by a Bronkhorst F-106AI-AGD-02-V airflow meter. In additions, multiple thermocouples are in-
Table 2: Component information

\begin{tabular}{|l|l|}
\hline Embedded Control System & NI 9038 CompactRIO \\
\hline Control \& DAQ Software & NI LabVIEW \\
\hline Exhaust Analyzer & Horiba MEXA-1700 \\
\hline $\begin{array}{l}\text { Main Chamber Pressure } \\
\text { Sensor }\end{array}$ & Kistler 7061C31 \\
\hline $\begin{array}{l}\text { Pre-chamber Pressure Sen- } \\
\text { sor }\end{array}$ & AVL GH15DK \\
\hline Intake air flow meter & $\begin{array}{l}\text { Bronkhorst F-106AI- } \\
\text { AGD-02-V }\end{array}$ \\
\hline $\begin{array}{l}\text { Intake \& Exhaust Pressure } \\
\text { Sensor (High Resolution) }\end{array}$ & $\begin{array}{l}\text { ETL-189-190M- } \\
\text { 10BARA }\end{array}$ \\
\hline $\begin{array}{l}\text { Intake \& Exhaust Pressure } \\
\text { Sensor (Low Resolution) }\end{array}$ & WIKA A-10 \\
\hline Spark Plug & NGK ER8EH (M8) \\
\hline Port Fuel Injector & Bosch EV14 \\
\hline PC Check Valve & $\begin{array}{l}\text { The Lee Company 558 } \\
\text { Series }\end{array}$ \\
\hline PC Gas Injector & $\begin{array}{l}\text { Clean Air Power SP- } \\
\text { 021 }\end{array}$ \\
\hline PC Mass Flow Controller & Brooks 5850EM \\
\hline
\end{tabular}

stalled to acquire temperatures of the cooling water, lubricating oil, intake and exhaust. The exhaust out emissions are measured by emissions analyzer from Horiba. Detailed component information can be found in table 2

\section{KAUST PRE-CHAMBER DESIGN}

The baseline engine before conversion has a diesel injector mounted at the center of the combustion chamber, located inside the diesel injector pocket. In order to reduce flow losses and to prevent flow choking, conventional prechambers typically features a throat diameter significantly larger than the typical diesel injector tip diameter. Therefore, the central injector hole is usually enlarged to allow the installation of the pre-chamber, especially in the case of engines converted from diesel. The design philosophy behind the KAUST pre-chamber is to minimize modifications to the engine cylinder head and thereby to inspect the possibility of a quick retrofit solution to the current diesel engines. The philosophy inevitably led to constraints in pre-chamber dimensions since the whole assembly must be able to fit inside the injector pocket (see figure 3 .

Subsequently, the final design features a pre-chamber assembly with a narrow throat which is perhaps unique compared to other pre-chamber shapes in the literature. The internal geometry of the pre-chamber body is shown in figure 4. For the purpose of studying the effect of pre-chamber volumes, pre-chambers are designed into three different volume categories denoted by the alphabets $\mathrm{A}, \mathrm{B}$ and $\mathrm{C}$. In each volume class, the pre-chamber nozzle area to prechamber volume ratio was varied into three different subcategories, indicated by the numbers 1,2 and 3 . The resulting design matrix can be observed in table 3 .

The pre-chamber volumes and nozzle sizes are determined following the findings of Gussak, who recommended B2 


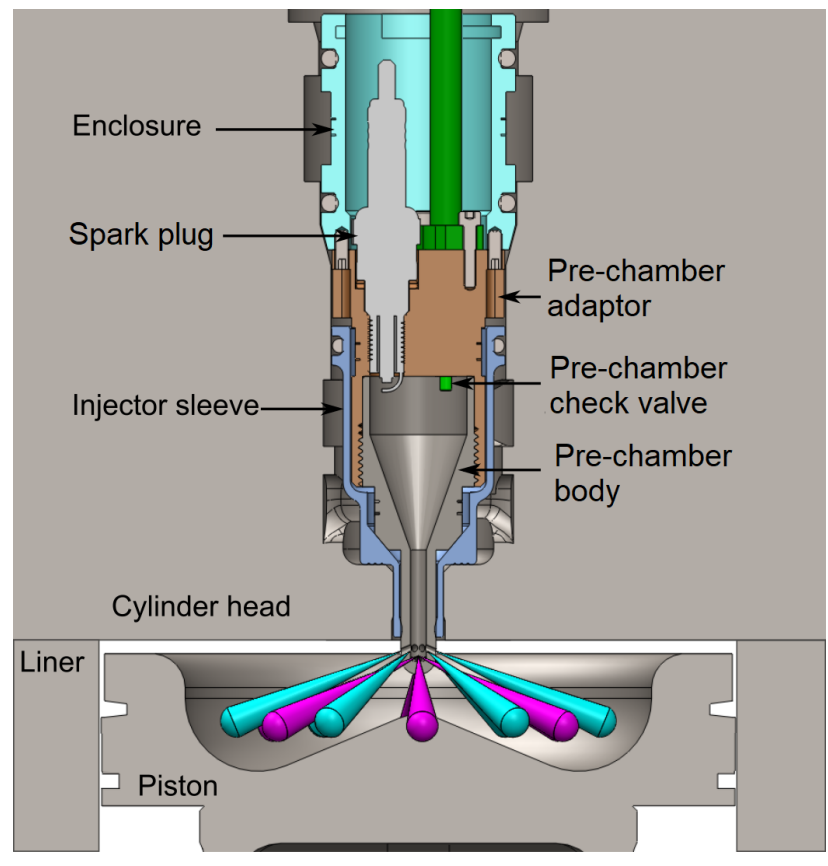

Fig. 3: Cross-section of pre-chamber installation

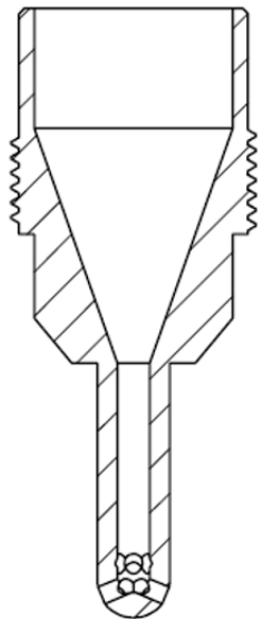

(a) Cross-section View

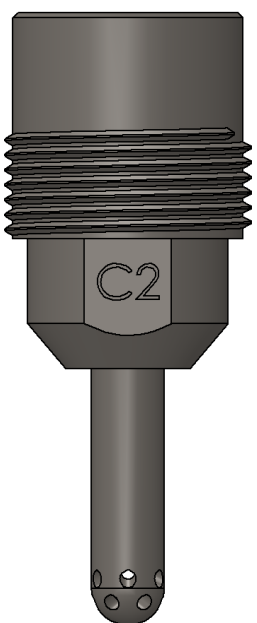

(b) CAD Model
Fig. 4: Pre-chamber body

configuration in his 1979 study [19]. In order to study the influence of the pre-chamber geometry, the pre-chamber design parameters, which are the PC volume and Nozzle area to $\mathrm{PC}$ volume ratios, were deviated from Gussak's recommendation. The PC volume was deviated $\pm 35 \%$ and for the nozzle area to PC volume ratio, deviation was $\pm 30 \%$ from Gussak's recommendations.

However, in this study, experiments are performed only with $\mathrm{C} 2$ pre-chamber as the aim of the study is to set up an initial study, assessing the performance of this unique pre-chamber geometry.C2 geometry corresponds to $3.4 \%$ of the clearance volume $(6.89 \mathrm{cc})$ and ratio from nozzle area to $\mathrm{PC}$ volume is $0.035 \mathrm{~cm}^{-1}$. The current study will be a stepping stone for an expanded parametric study where the pre-chamber volumes and nozzle sizes will be varied in order to analyze the effects of the pre-chamber geometry.
Table 3: Design matrix

\begin{tabular}{|c|c|c|c|c|}
\hline & lume Class & A & B & C \\
\hline & Slearance Vol & 1.6 & 2.5 & 3.4 \\
\hline & C Volume [cc] & 3.245 & 5.070 & 6.896 \\
\hline & C Volume $\left[\mathrm{cm}^{-1}\right]$ & Nozzl & Diame & $\mathrm{r}[\mathrm{mm}]$ \\
\hline 1 & 0.025 & 0.93 & 1.16 & 1.35 \\
\hline 2 & 0.035 & 1.10 & 1.37 & 1.60 \\
\hline 3 & 0.045 & 1.24 & 1.56 & 1.81 \\
\hline
\end{tabular}

Parameters written in bold refers to the pre-chamber geometry $\mathrm{C} 2$ which is the only tested pre-chamber in this study

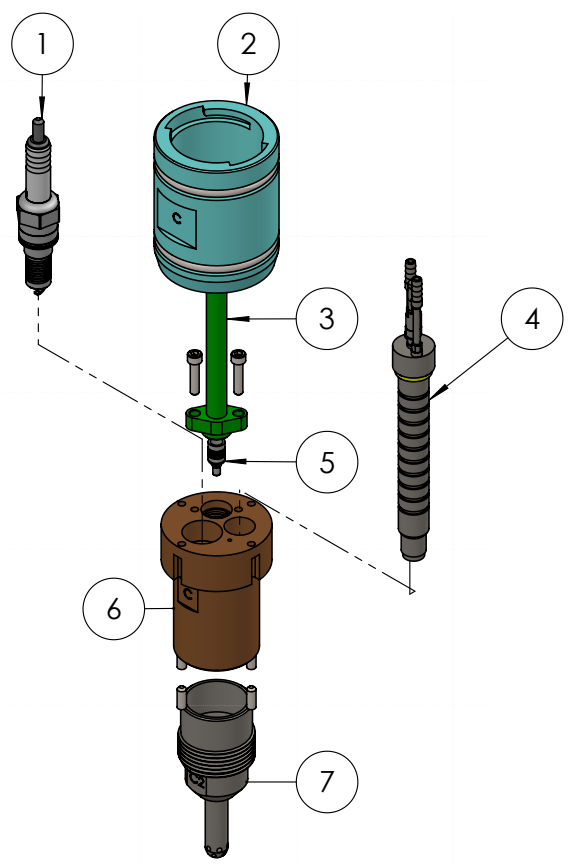

Fig. 5: Exploded view of pre-chamber assembly:

1. Spark plug 2. Enclosure 3. Gas supply pipe 4. Pressure sensor 5. Miniature check valve 6. Adaptor 7. Pre-chamber body

The pre-chamber assembly (see figure 5 consists of three main parts: the pre-chamber body, the pre-chamber adaptor and the enclosure. The pre-chamber body contains the actual pre-chamber volume where combustion occurs. Due to limited circumferential area of the tip, the number of prechamber nozzles was increased to 12 to reduce the nozzle diameter. The pre-chamber body was manufactured with Inconel 625 due to the ulterior strength of the material which will prevent failure of the pre-chamber, especially for the high load studies. The nozzle holes are divided into two planes where each plane contains 6 nozzles. The two planes are offset by 15 degrees in an attempt to improve distribution of pre-chamber jets into the main combustion chamber.

The pre-chamber body is screwed onto the pre-chamber adaptor. The latter accommodates the spark plug, pressure transducer and the gas injection arrangement. The adaptor is made out of bronze in order to enable compression tightening of pre-chamber body against the mating surface of the adaptor. The material also assists in conducting heat from the pre-chamber assembly owing to the good thermal conductivity of bronze. A miniature check valve is fitted 
inside the gas supply passage within the adaptor, which serves to prevent the back flow when pre-chamber combustion occurs, in addition to permitting fuel injection into the pre-chamber during the gas exchange period. A gas pipeline is connected onto the top surface of the adaptor, which is fed by a solenoid-controlled gas injector.

The pre-chamber body is connected to the enclosure by means of four set-screws. The function of the enclosure is to seal the pre-chamber assembly from the fuel gallery located within the cylinder head. It also act as a spacer for clamping down the pre-chamber assembly from top. The complete assembly is nestled inside the injector pocket and enclosure is sealed to prevent ingress of lubricating oil from the lubrication system of the valve train.

\section{OPERATING CONDITION AND METHODOLOGY}

The engine was operated at an intake pressure of 1 bar and the air temperature was maintained at $30^{\circ} \mathrm{C}$ by means of the air heater. The engine cooling water and lubricating oil temperatures were kept constant at $75^{\circ} \mathrm{C}$ and $80^{\circ} \mathrm{C}$ respectively. The experiments were performed at the engine speed of $1200 \mathrm{rpm}$. The main chamber was fueled with ethanol ( $96 \%$ by vol.) and the pre-chamber was fueled with methane $(99.5 \%$ purity).In order to avoid complexities associated with liquid fuel injection inside the prechamber (e.g. wall wetting), methane was selected as the pre-chamber fuel. On the other hand, a fuel with high octane rating should be chosen as main chamber fuel to avoid end-gas auto-ignition or knock. In such case, methane is also a suitable fuel for main chamber. However, due to reduced availability of methane, ethanol was chosen as the main chamber fuel owing to its high knock resistance. The tabular form of the operating conditions can be found in table 4

Table 4: Operating condition

\begin{tabular}{|l|c|c|}
\hline Engine Speed & 1200 & RPM \\
\hline Cooling Water Temperature & $75 \pm 2$ & ${ }^{\circ} \mathrm{C}$ \\
\hline Lubricating Oil Temperature & $80 \pm 2$ & ${ }^{\circ} \mathrm{C}$ \\
\hline Intake Temperature & $30 \pm 0.5$ & ${ }^{\circ} \mathrm{C}$ \\
\hline Intake Pressure & $1 \pm 0.05$ & bar \\
\hline Exhaust Pressure & $1 \pm 0.05$ & bar \\
\hline MC Fuel & Ethanol $(96 \%$ by vol.) \\
\hline MC Fuel Injection Timing & -330 & CAD aTDC \\
\hline MC Fuel Injection Pressure & 4 & bar \\
\hline PC Fuel & Methane $99.5 \%$ purity) \\
\hline PC Fuel Injection Timing & -360 & CAD aTDC \\
\hline PC Fuel Injection Pressure & 6 & bar \\
\hline
\end{tabular}

The lean limit of the engine was defined as the limit where the co-variance of gross IMEP (CoV of IMEPg) exceeds $5 \%$. The experiment commenced with passive pre-chamber mode and the main chamber fuel injection was decreased until the lean limit was reached. Further reduction of main chamber fuel beyond this points required pre-chamber fueling to maintain $\mathrm{CoV}$ of IMEPg below the combustion stability limit. For a given pre-chamber fueling rate, the lean limit was again explored by reducing the main chamber fueling until the combustion stability limit was achieved. Further reduction of main chamber fuel required improving the pre-chamber mixture strength, which was realized by increasing pre-chamber fuel injection rate. In this way, the lean limit was observed for each level of pre-chamber fueling rate.

For each overall excess air ratio $(\lambda)$ case, further advancing the spark timing led to $\mathrm{CoV}$ of IMEPg exceeding 5\%, except for passive pre-chamber case where advancing the spark timing increased the knock intensities beyond the knock limit. For the most retarded spark timing, further retarding the spark timing resulted in combustion phasing (CA50) exceeding 10 CAD aTDC and hence were not reported in this paper. However, during the experiments, running the engine at $5 \% \mathrm{CoV}$ led to numerous misfire events leading to accumulation of unburned fuel inside the exhaust which causes combustion or explosion events inside the exhaust pipe. In order to protect the engine and the exhaust line, the engine was not operated at $5 \% \mathrm{CoV}$ of IMEPg and the reported data points corresponds to $2-4 \% \mathrm{CoV}$ of IMEPg.

For each operating point, the data was recorded for 500 consecutive cycles and the average data were reported. For a specific pre-chamber fueling rate, spark timing sweeps were performed. For operating at various global lambda condition in the active pre-chamber mode, the pre-chamber fueling rate was changed from 1 to 6 liters per minute. The back pressure on the pre-chamber check valve depends on the pressure inside the pre-chamber during the injection window which is found to be around 1 bar. Based on the pressure and temperature at the mass flow controller, the methane density can be calculated. Using the calculated density, the pre-chamber fueling rate was found to be varied from $1 \mathrm{mg}$ to $9 \mathrm{mg}$ per cycle on the mass basis for various global lambda conditions.

\section{HEAT RELEASE ANALYSIS}

In order to assess the engine performance, the heat release analysis was performed. In pre-chamber combustion, the heat release analysis is complex due to the mass transfer and energy transfer between the two chambers. Duong et al. [20] investigated into the multi-chamber heat release analysis by implementing a mass transfer model between the main and the pre-chamber based on the measured pressure of the two chambers. The same methodology was applied in this study. Based on the first law of thermodynamics, the heat release rate of the pre and main chamber can be derived as

$$
\begin{gathered}
\frac{d Q_{M}}{d \theta}=\frac{\gamma}{\gamma-1} P_{M} \frac{d V_{M}}{d \theta}+\frac{1}{\gamma-1} V_{M} \frac{d P_{M}}{d \theta}-C_{p} T_{P, M} \frac{d m}{d \theta} \\
\frac{d Q_{P}}{d \theta}=\frac{1}{\gamma-1} V_{P} \frac{d P_{M}}{d \theta}+C_{p} T_{P, M} \frac{d m}{d \theta}
\end{gathered}
$$

where the subscript $\mathrm{P}$ and $\mathrm{M}$ refers to pre-chamber and main chamber respectively. The specific heat ratio $(\gamma)$ and specific heat capacity at constant pressure $\left(C_{p}\right)$ were calculated based on the mixture fraction of main chamber trapped mass and bulk gas temperature of the charge. The 
latter was calculated from the main chamber pressure trace using the Ideal gas law, based on the conditions at inlet valve closing. The equation for mass transfer between the two chambers is shown below.

$$
d m=\frac{C_{d} A_{T} P_{P}}{\sqrt{R T_{P}}}\left(\frac{P_{M}}{P_{P}}\right)^{\frac{1}{\gamma}}\left(\frac{2 \gamma}{\gamma-1}\left(1-\left(\frac{P_{M}}{P_{P}}\right)^{\frac{\gamma-1}{\gamma}}\right)\right)^{\frac{1}{\gamma}}
$$

The convention is taken to be positive when the mass is being transferred from pre-chamber to the main chamber. In other words, the mass transfer rate $(d m)$ is positive when the pressure difference $(\Delta P)$ is positive. In such scenario, the temperature calculated from pre-chamber pressure trace is used in the equation and vice verse [21]. When the main chamber pressure is higher than the pre-chamber, the pressure ratios need to be inverted and the main chamber pressure and temperature has to be used in the first term on the right side of the equation.

Here, $\left(C_{d}\right)$ is the discharge coefficient of the pre-chamber while $\left(A_{T}\right)$ represent the total nozzle area of the prechamber. The detailed information on the heat release analysis can be found in the paper published by Duong et al. in 2014 [20]. The discharge coefficient is an important parameter to determine the mass transfer rate. However, this parameter depends on pressure ratio between the pre and main chamber and also relates to the mixture density at a particular point in a cycle. Hence, the discharge coefficient values were extracted from the GT-Power calculation based on the three pressure analysis. Additional details on the three-pressure analysis procedure in the GT-Power model were provided in the following sections.

The total heat release from the cylinder is calculated as the summation of the heat release from the two chambers and the loss mechanisms as shown below.

$$
\frac{d Q}{d \theta}=\frac{d Q_{M}}{d \theta}+\frac{d Q_{P}}{d \theta}+\frac{d Q_{H t}}{d \theta}+\frac{d Q_{C r}}{d \theta}+\frac{d Q_{B l}}{d \theta}
$$

The last three terms of the equation reflects the convective heat transfer losses, crevice losses and the blow-by losses typical to an in-cylinder heat release analysis. The pre and main pressure traces were corrected for charge leakage between the pressure sensor to the charge amplifier as well as for the TDC offset. Charge leakage was corrected using a linear compensation factor and the motoring pressure trace and the TDC offset was determined by tuning the heat release of the motoring case. Woschni heat transfer model was used to evaluate convective heat transfer losses [22]. The crevice volume and blow-by losses were added to result in a flat zero heat release curve using a motoring cycle. The results will be discuss in the subsequent sections.

\section{RESULTS AND ANALYSIS}

The experiments were performed at low load condition with intake pressure fixed at 1 bar. The engine was operated first in passive pre-chamber mode and then the main chamber fueling was progressively reduced until it could no longer sustain stable combustion. The knock limit of the engine was taken as the knock intensity $(\mathrm{KI})$ above 0.5 bar. In passive mode, moderately high knock intensity $(\approx$
$0.7 \mathrm{KI}$ ) was experienced at advanced spark timings. Hence, the spark timing was retard to -12 CAD aTDC. Further retardation of the spark timing results in unfavorable combustion phasing and thus only the data at -12 CAD aTDC was reported in passive operating mode.

As the combustion becomes leaner, in order to sustain stable combustion, the pre-chamber flow rate was varied from 1 liters per minute up to 6 liters per minute. The latter flow rate results in the highest excess air ratio $(\lambda)$ or the lean limit. Beyond this point, increasing the pre-chamber fuel did not reduce the CoV of IMEPg beyond the combustion stability limit, which is taken as the $5 \% \mathrm{CoV}$ of gross IMEP. The amount of fuel supplied to the pre-chamber is presented based upon energy basis as the percentage of combined FuelMEP from main and pre-chamber fuel injections, as shown in the plot legend box of all the figures. For example, PC 0.025 case refers to $2.5 \%$ of total fuel energy supplied through the pre-chamber. To estimate the FuelMEP, fuel flow measurements from main and prechamber fuel systems were used. The global air-excess ratio is also mentioned in brackets beside the pre-chamber FuelMEP ratio in the legend boxes. The global or overall excess air ratio $(\lambda)$ were calculated from emission measurements using the concentrations of major exhaust species provided by the exhaust gas analyzer.

In figure 6, the combustion efficiency and gross indicated efficiency are plotted against the spark timing. The crank angle position of spark discharge did not have significant influence on the combustion efficiency. As the operation became leaner, the increased $\mathrm{CO}$ and $\mathrm{HC}$ emissions were observed, indicating poor utilization of fuel energy. This results in steady decline of indicated efficiency as the combustion became lean.

Moreover, the decline of indicated efficiency can also be attributed to the long combustion duration at lean conditions as shown in figure 7 At relatively rich condition and for passive pre-chamber case, the combustion duration is significantly short, which enhance the effective expansion stroke, thus achieving higher work done on the piston during the expansion stroke. Subsequently, the IMEP and gross indicated efficiency were improved. Combustion phasing is also important to extract maximum possible work as shown in part (b) of figure 7

Similar to the conventional SI combustion, the spark timing determine the combustion phasing and thus crank angle degree of CA50 monotonically increases with later spark timing as shown in part (c) of figure 7). At relatively rich condition, the combustion was stable at a range of spark timing closer to TDC. However, near the lean limit, the operating window move away from TDC as shown in the plot. This observation was of interest to the authors and further analysis was conducted to assess the pre-chamber mixture strength near the lean limit.

One noteworthy fact is that among different pre-chamber fueling rates, for the two leanest case with 0.1 and $0.14 \mathrm{PC}$ FuelMEP to total FuelMEP ratio, the volume of fuel in- 


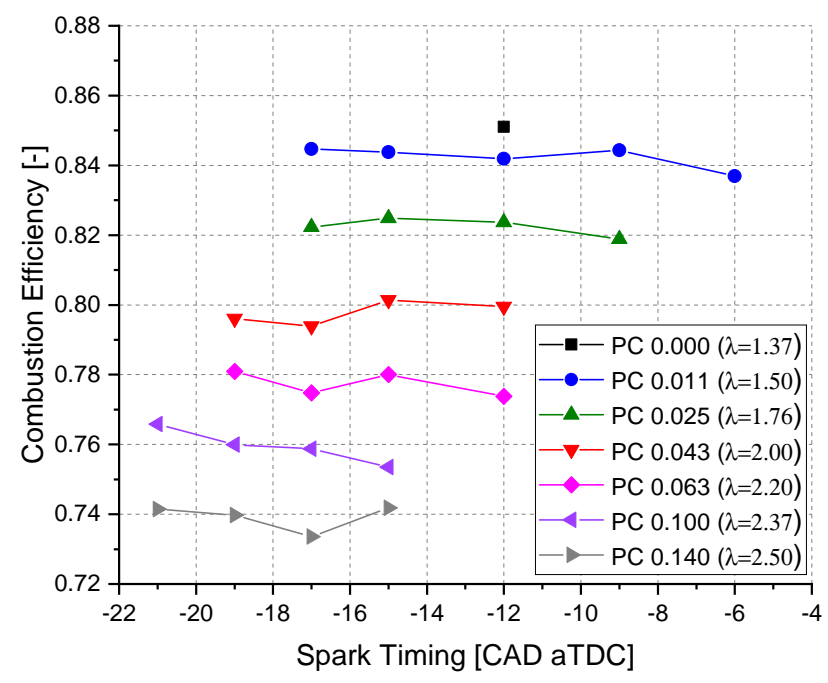

(a)

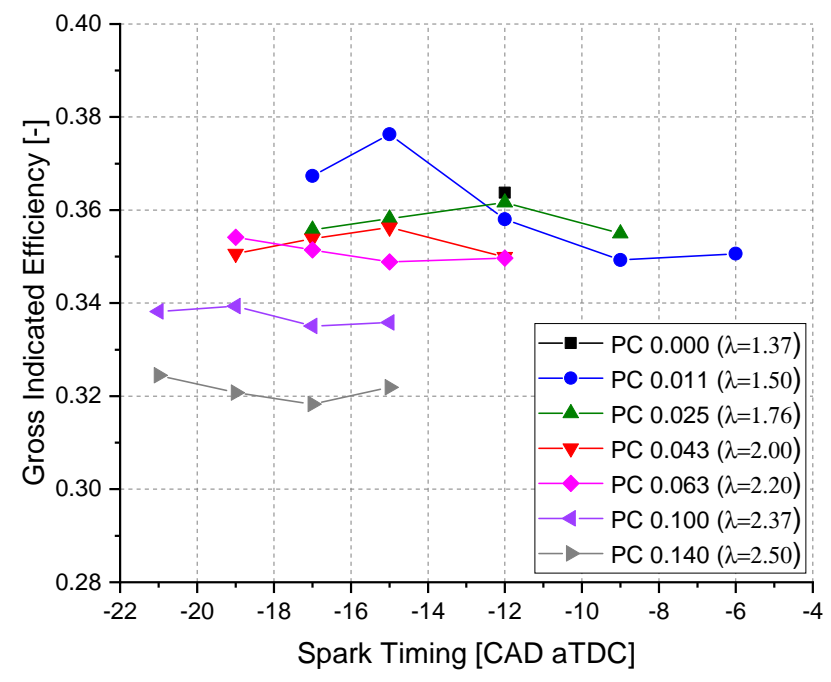

(b)

Fig. 6: Pre-chamber efficiency at various PC FuelMEP ratios and overall air excess ratio: (a) Combustion efficiency and (b) Gross indicated efficiency

jected into the pre-chamber was high enough to completely flush the pre-chamber. The PC fuel volume, after expansion through the check valve, exceeded the pre-chamber volume and, inevitably, some portion of the injected fuel is discharged into the main chamber. In such a condition two possibilities arise. One scenario is that the spilled fuel is pushed back into the pre-chamber during the compression stroke. Another possibility is that the spilled fuel mixed with the main chamber charge and further enriched the main chamber mixture strength.

Gussak employed a model relying on instantaneous compression ratio and density to assess the pre-chamber mixture strength [23]. Ashish et al. also employed a similar model with an assumption that all the over-spilled fuel was pushed back into the pre-chamber during the compression stroke [24]. Details methodology can be found in the above two references. In this study, the authors would like to explore the second possibility where the over-spilled fuel is considered as part of the main chamber premixed charge. The conceptual model can be found in figure 8 . Instead of

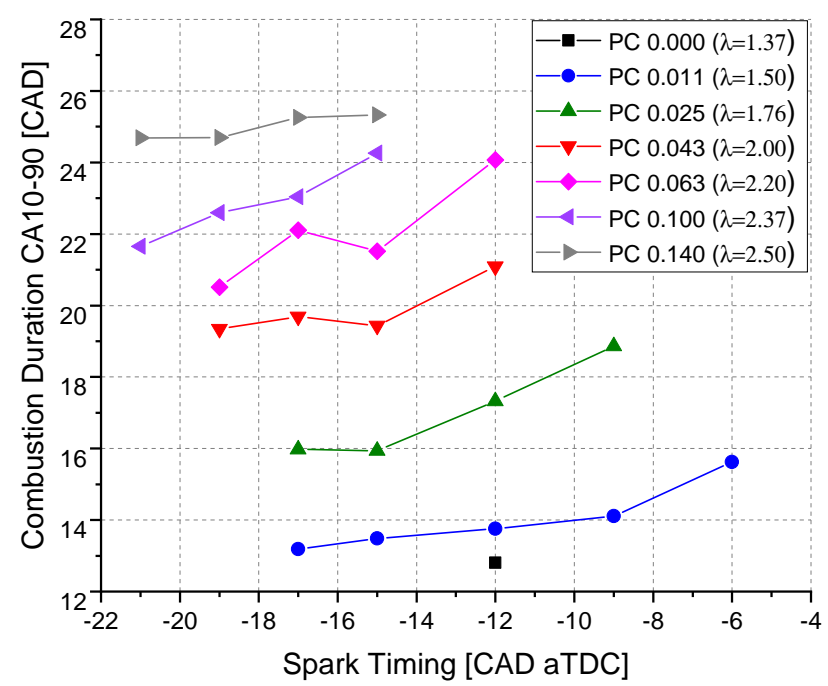

(a)

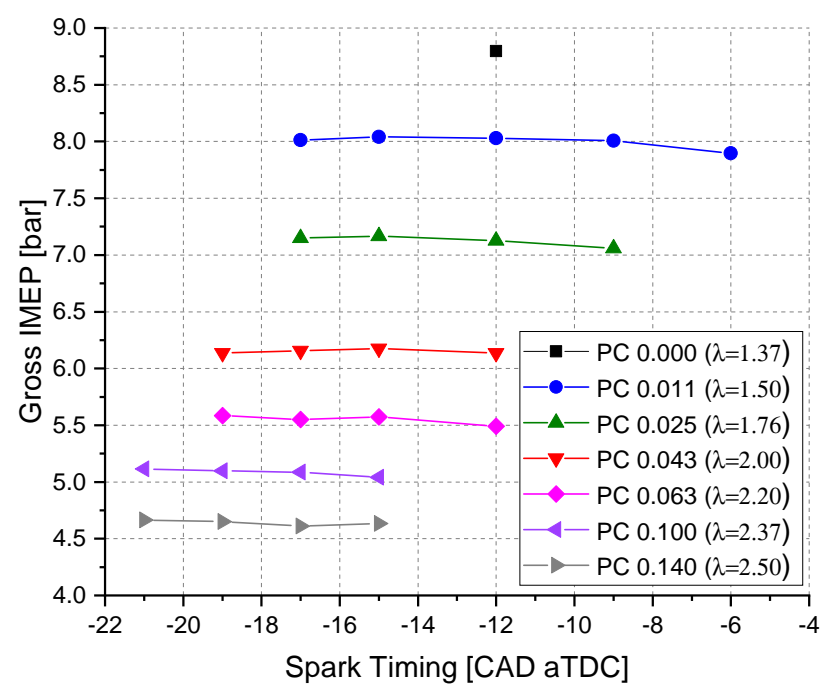

(b)

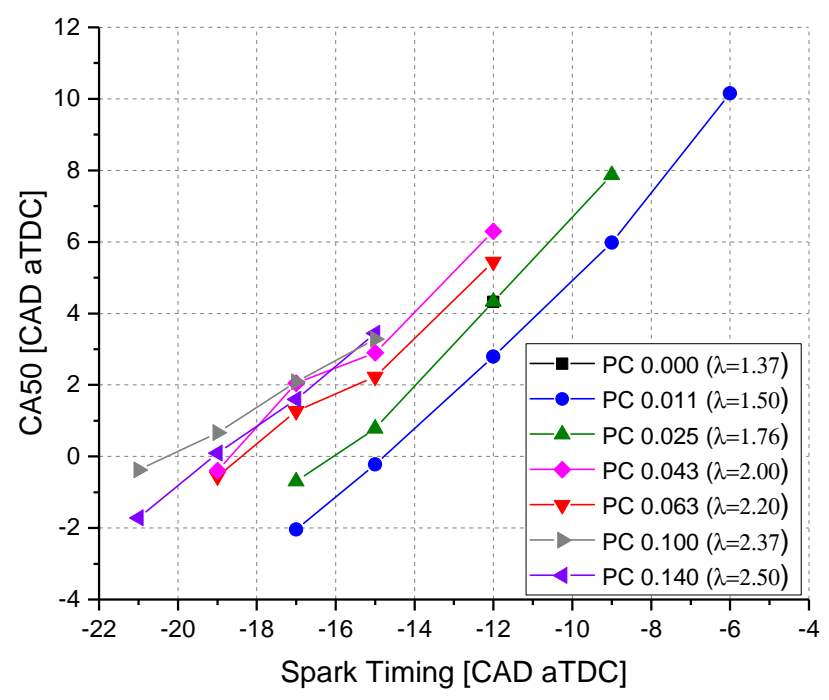

(c)

Fig. 7: Pre-chamber performance at various PC FuelMEP ratios and overall air excess ratio: (a) Combustion duration from $10-90 \%$ heat release, (b) Gross IMEP and (c) Combustion phasing (CA50) 


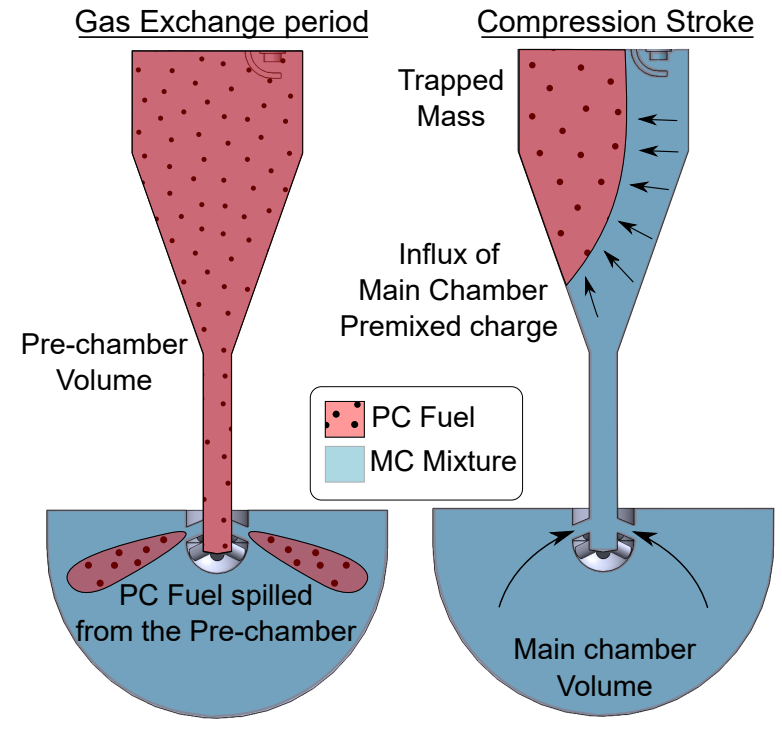

Fig. 8: Conceptual model for pre-chamber equivalence ratio

using the instantaneous compression ratio, the rate of mass transfer between the pre and main chambers as shown in equation 4 is used to determine the amount of influx main chamber charge during the compression stroke.

From these observation, a hypothetical model was developed for over-spill case, assuming that the pre-chamber will only trap the volume of injected fuel equal to its volume should the injected volume exceeds the pre-chamber volume. The surplus fuel is assumed to mixed with main chamber charge. The incoming main chamber mixture is assumed to be homogeneous. The proposed model helps to understand the assumption.

Using the above simplified assumptions, the initial trapped fuel inside the pre-chamber following an injection event can be determined. The discharge coefficients of the prechamber nozzles in the forward and reverse direction were determined using the three pressure analysis (TPA) procedure in the GT-Power model.

\section{GT-POWER 1-D SIMULATION}

A 1-D model was setup in the GT-Power 2018 version using the geometrical parameters of the experimental engine such as the exhaust and intake manifold length, diameters of the intake and exhaust valves, the valve lift profiles and engine cylinder dimensions. Moreover, the boundary conditions such as exhaust and intake temperatures and pressures, measured from the experiments were logged into the 1-D model to capture the in-cylinder conditions. Emission values measured from the Horiba exhaust gas analyzer were used to dictate the combustion efficiency of the main chamber template.

Due to lack of availability of a dedicated pre-chamber template in the GT-Power 2018 software, an engine cylinder template was used to mimic the pre-chamber. A userdefined object was used to lock the pre-chamber at the BDC position throughout the cycle. Pre-chamber volume was specified as the clearance volume of the engine cylinder template. An orifice object is used to simulate pre-chamber nozzles which defines the nozzle diameter, nozzle length and the number of nozzles.

In the three pressure analysis (TPA), the inlet and exhaust pressure traces were used to match the pumping loop of the simulated pressure trace to that of the experimental value on the P-V diagram. The pre-chamber and main chamber pressure traces were incorporated into the respective model templates and the cylinder pressure calibration mode was employed to extract combustion related data. The start of combustion in the pre-chamber and the main chamber is manually adjusted to achieve satisfactory phasing between the simulated and the measure pressure traces. Simultaneously, the discharge coefficients through the pre-chamber nozzles in forward and reversed directions were determined by matching the simulated main chamber and pre-chamber pressure trace to that of the experimental counterpart.

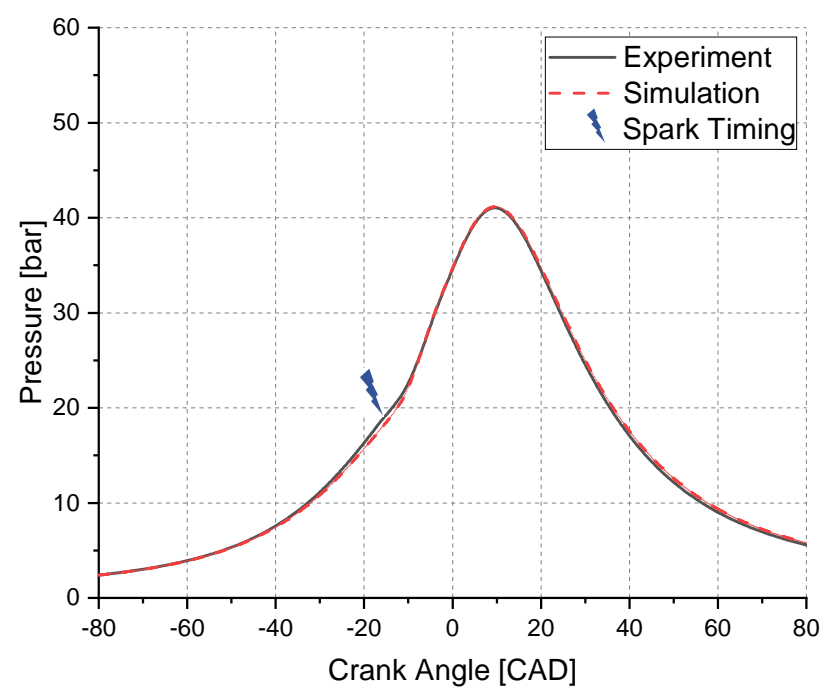

(a)

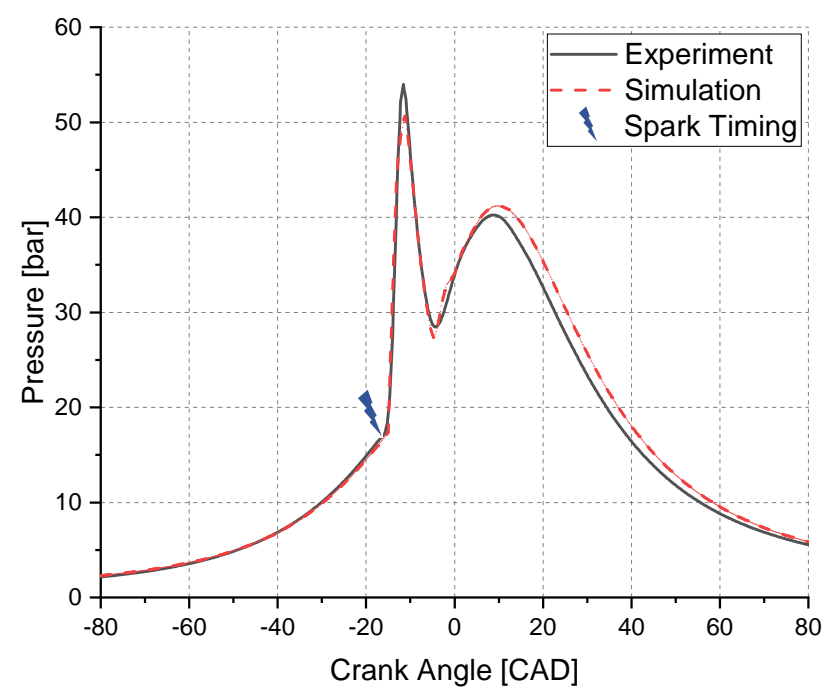

(b)

Fig. 9: Simulated and experimental pressure traces at the lean limit (PC 0.140 $(\lambda=2.5)$ ):

(a) Main chamber and (b) Pre-chamber 
A good match with main chamber pressure trace was obtained for all cases of main chamber fuel rates. Here the pressure trace at the lean limit is shown in figure 9 (a). For the pre-chamber pressure trace, as shown in figure 9 (b), the model could capture the compression stroke up to the spark timing but could not accurately capture the pre-chamber combustion event. The same behavior was observed for the two over-spilling cases studied. However, here, the emphasis is on the mixture strength or equivalence ratio at the time of spark and it is evident that the model can capture the pre-chamber pressure trace during the compression stroke satisfactorily. Hence, the model prediction of mass transfer from main chamber to pre-chamber is deemed sufficiently accurate to determine the discharge coefficients of the prechamber nozzles.

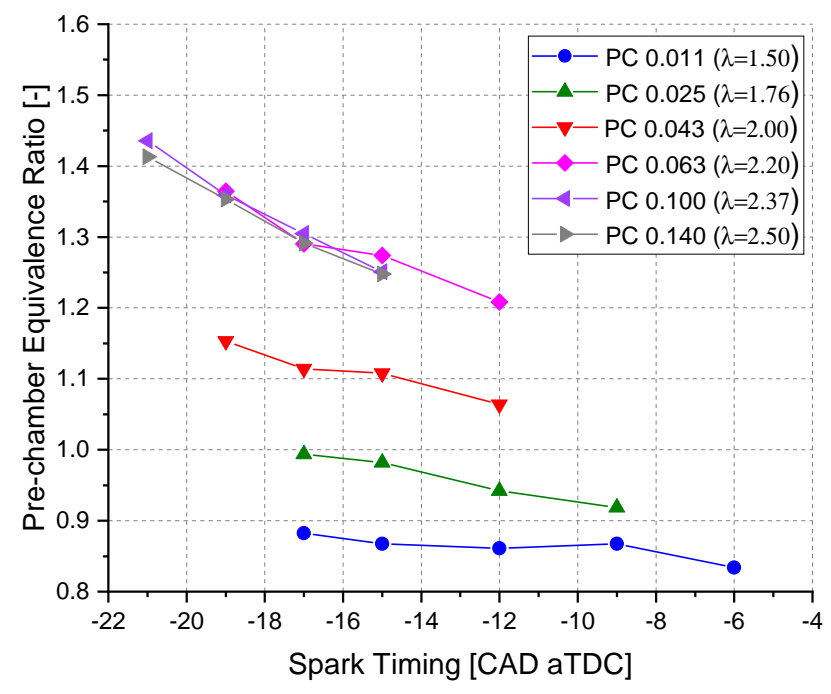

Fig. 10: Pre-chamber equivalence ratio distribution

From the TPA, the discharge coefficient in the forward direction, i.e. when the pre-chamber pressure is higher than the main chamber, was found to be 0.34 . The discharge coefficient in the reverse direction is found of be 0.33 . Compared to the values used by Duong et al.[20], which is 0.6, the discharge coefficient is much lower which may be contributed to the long and narrow throat design of the prechamber.

The equivalence ratio of the pre-chamber was determined using the discharge coefficients for all the operating points. The GT-Power model predictions were similar to the conceptual model results and here the latter is reported. As shown in figure 10 , the pre-chamber equivalence ratio is a strong function of spark timing and for the three lean cases from $\lambda=2.20$ to $\lambda=2.50$, the pre-chamber equivalence ratios collapse for a particular spark timing range. The reason for this collapse is that, at these three conditions, the volume of fuel trapped by pre-chamber was similar prior to dilution by main chamber charge during the compression stroke. For relatively rich operation around $\lambda=1.5$ to 2 , the pre-chamber equivalence ratio was found to be around stoichiometry. Further reduction of main chamber fueling would deteriorate the pre-chamber equivalence ratio and would lead to combustion instability.

\section{INDICATED SPECIFIC EMISSIONS}

The engine out emissions were plotted in figure 11 where the carbon monoxide (CO), unburned hydrocarbon (HC) and nitrous oxides (NOx) emissions are shown. The mass of the emission species are normalized by the gross indicated power output of the engine. As shown in plot (a) and (b), the pre-chamber suffers from incomplete combustion as indicated by high $\mathrm{CO}$ and $\mathrm{HC}$ emissions. The presence of the narrow and long throat passage would lead to excessive flow restriction when combustion occurs in the pre-chamber. This flow restriction could impose severe quenching of active radicals produced by rich combustion inside the pre-chamber. The issuance of pre-chamber jets are limited to a narrow window when there is a significant pressure difference between the pre and the main chamber. Flow impedance may lead to partial combustion products being trapped inside the pre-chamber and could lead to excessive $\mathrm{CO}$ and $\mathrm{HC}$ emissions.

In the case of unburned hydrocarbons, since the prechamber fuel injected mass was significantly less than the main chamber fuel for all the operating conditions, it can be consider that the low combustion efficiency results from poor ignition of main chamber charge. Moreover, the $\mathrm{CO}$ emissions were significantly lower than the $\mathrm{HC}$ emissions. These observations indicate that the some of the fuel injected into the main chamber were not converted and were discharged into the exhaust. Hence, it can be concluded that the ignition energy of the pre-chamber is not high enough to attain favorable combustion efficiency.

Pre-chamber combustion, being a lean burn operating concept, is known to reduce NOx emission due to lower bulk gas temperatures below the NOx formation temperature. However, the ignition energy of a pre-chamber is a strong function of its volume. The amount of fuel trapped scales with the pre-chamber volume and distinct pressure rises during pre-chamber combustion is usually observed in larger pre-chambers. The pre-chamber volume used in this study is comparatively large, as stipulated by the strong pressure rise in pre-chamber following a spark discharge.The strong pressure rise correlates to higher bulk gas temperatures leading to some NOx emissions, often termed as pre-chamber source NOx or in other words, NOx originated from pre-chamber. The NOx emissions displayed a downward trend as the overall combustion become leaner, a direct effect of lower temperature during combustion.

\section{CONCLUSION}

The following conclusions can be observed from the current study.

1. The narrow throat pre-chamber design reveals high combustion losses. The losses may be traced back to the flow restriction of the pre-chamber geometry leading to poor mass transfer between the pre and the main chamber. The small throat diameter is thought to result in high flow impedance which could lead 


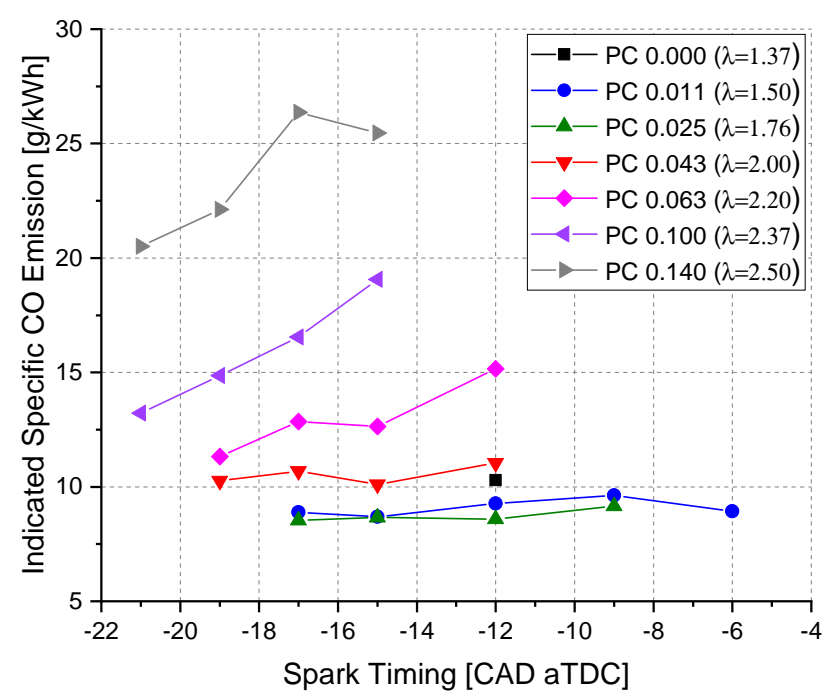

(a)

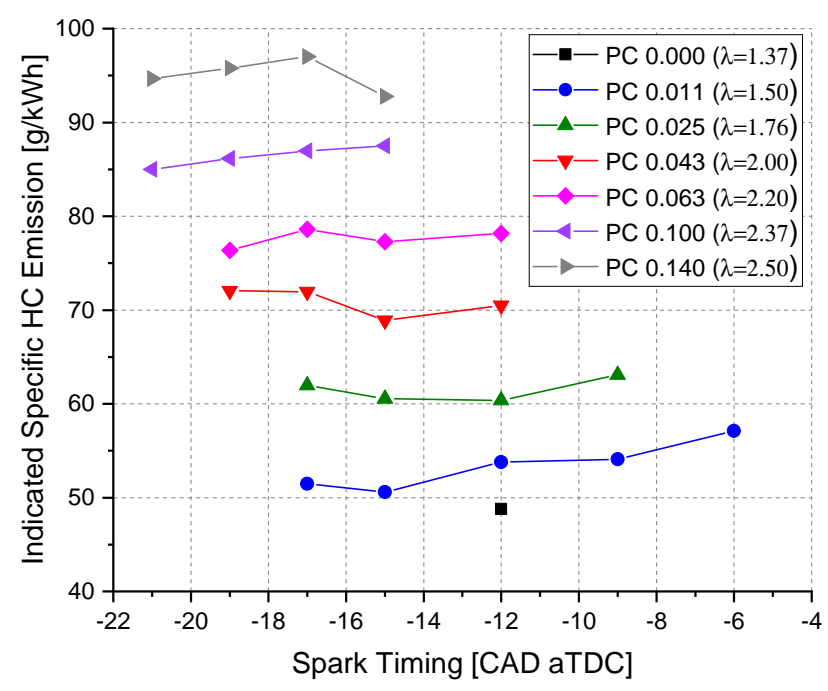

(b)

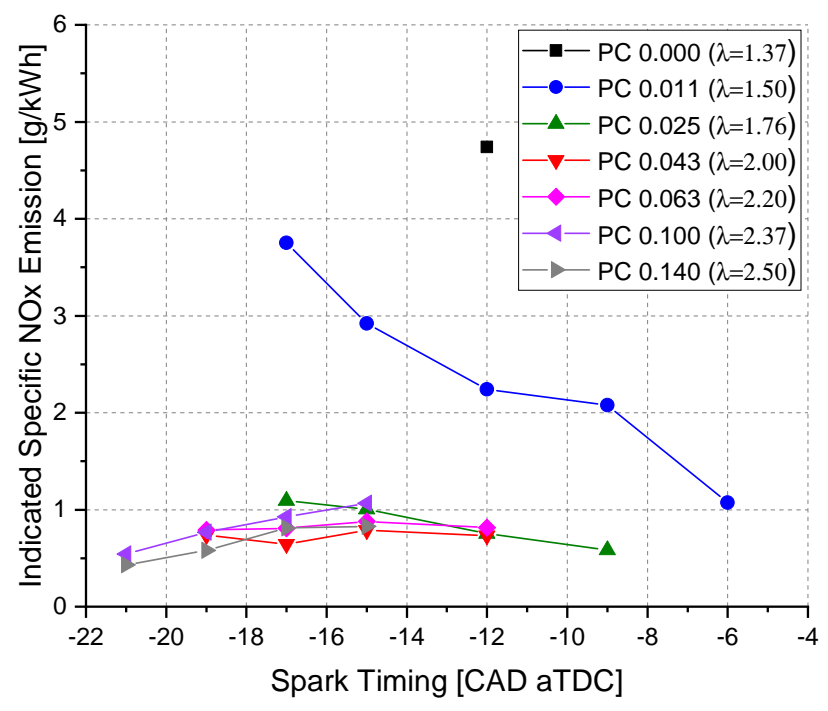

(c)

Fig. 11: Indicated specific emissions:

(a) Carbon Monoxide (CO) (b) Unburned Hydrocarbons (UHC) and (c) Oxides of Nitrogen (NOx) to high residence time for the burned products inside the pre-chamber following the pre-chamber combustion. The longer the residence time is, the lower the reactivity of the partially burned products. On the other hand, the throttling effect induced by the narrow throat could result in excessive quenching, further reducing the reactivity of pre-chamber products. Since the unburned hydrocarbon content in the exhaust is excessive, it could be concluded that process where the pre-chamber jets ignite the main chamber charge is largely inefficient. Detailed CFD studies need to be performed to assess the combustion inside the prechamber for further understanding of the observation. Moreover, experiments were planned in the near future to examine the ignition characteristics of the prechamber charge using an optically-accessible engine.

2. As the combustion become leaner, it is necessary to improve the mixture strength or equivalence ratio inside the pre-chamber. During the compression stroke, the pre-chamber charge is continually diluted by the incoming lean mixture from the main chamber as the piston moves towards TDC. This hypothesis is further supported by the downward trend of pre-chamber equivalence ratio as the spark timing moves towards the TDC. Hence, combustion stability at lean conditions can be promoted by improving the pre-chamber mixture strength. However, at the leanest operating point, the incoming main chamber charge is too lean and the pre-chamber mixture strength is not sufficiently high to maintain stable combustion. Thus it can be concluded that a lean limit exists for a specific pre-chamber geometry.

3. Using the conceptual model, the maximum amount of fuel trapped in the pre-chamber during a pre-chamber injection event is limited to the pre-chamber volume. In the $\mathrm{C} 2$ geometry, the maximum pre-chamber equivalence ratio calculated was found to be around 1.4 which corresponds to Gussak's recommendation of pre-chamber lambda $(\lambda)$ of 0.7 . The model calculations are inline with GT-Power results and the approach could lead to renewed understanding of prechamber equivalence ratio.

4. In order to ensure ignition inside the pre-chamber, the spatial-averaged pre-chamber equivalence ratio must be within a certain range. This range tends to occur on the fuel rich condition and corresponds to Gussak's findings. However, it is important to estimate the equivalence ratio close to the spark plug as it can reveal additional insights into ignition phenomenon inside the pre-chamber. Moreover, the turbulence inside the pre-chamber can affect the homogeneity of prechamber charge and can influence the pre-chamber combustion characteristics. With the help of physical models and CFD simulations, it would be beneficial to study the turbulence field inside the pre-chamber.

5. The current pre-chamber tested $(\mathrm{C} 2)$ has a volume and nozzle area ratio different from Gussak's recommendation. Subsequent parametric studies are required 
to assess the same operating conditions with different pre-chamber volumes and nozzle opening area in order to assess the effects of pre-chamber geometries. Especially in the case of NOx emissions, limiting the pre-chamber pressure rise by means of either reducing the pre-chamber volume or by increasing the nozzle area could further drive down the NOx emissions.

\section{REFERENCES}

[1] Zabetakis, M. G. Flammability characteristics. Flammability characteristics of combustible gases and vapors 20-27 (1965).

[2] Biswas, S. Physics of Turbulent Jet Ignition Sayan Biswas Mechanisms and Dynamics of Ultra-lean Combustion (2018).

[3] Toulson, E., Schock, H. J. \& Attard, W. P. A Review of Pre-Chamber Initiated Jet Ignition Combustion Systems (2010).

[4] Oppenheim, A. K. Prospects for Combustion in Piston Engines. SAE Technical Paper Series 1 (2002).

[5] Yamaguchi, S., Ohiwa, N. \& Hasegawa, T. Ignition and burning process in a divided chamber bomb. Combustion and Flame 59, 177-187 (1985).

[6] Attard, W., Fraser, N., Parsons, P. \& Toulson, E. A Turbulent Jet Ignition Pre-Chamber Combustion System for Large Fuel Economy Improvements in a Modern Vehicle Powertrain. SAE International Journal of Engines 3, 2010-01-1457 (2010).

[7] Gentz, G. R. \& Toulson, E. Experimental Studies of a Liquid Propane Auxiliary Fueled Turbulent Jet Igniter in a Rapid Compression Machine. SAE International Journal of Engines 9, 2016-01-0708 (2016).

[8] Gentz, G. R., Gholamisheeri, M. \& Toulson, E. A study of a turbulent jet ignition system fueled with iso-octane: Pressure trace analysis and combustion visualization. Applied Energy 189, 385-394 (2017).

[9] Shah, A., Tunestal, P. \& Johansson, B. Investigation of Performance and Emission Characteristics of a Heavy Duty Natural Gas Engine Operated with PreChamber Spark Plug and Dilution with Excess Air and EGR. SAE International Journal of Engines 5, 2012-01-1980 (2012). 2012-01-1980

[10] Shah, A., Tunestål, P. \& Johansson, B. CFD Simulations of Pre-Chamber Jets' Mixing Characteristics in a Heavy Duty Natural Gas Engine. SAE Technical Paper Series 1 (2015).

[11] Shah, A., Tunestal, P. \& Johansson, B. Effect of Pre-Chamber Volume and Nozzle Diameter on PreChamber Ignition in Heavy Duty Natural Gas Engines. In SAE Technical Paper Series, vol. 1 (2015).

[12] Shah, A., Tunestal, P. \& Johansson, B. Scalability Aspects of Pre-Chamber Ignition in Heavy Duty Natural Gas Engines. SAE Technical Paper Series 1 (2016).
[13] Sun, S., Ma, Y., Cui, L., Ma, X. \& Shuai, S.-J. Effect of Single and Double-Deck Pre-Chamber Designs to the Combustion Characteristics of Premixed $\mathrm{CH} 4$ /Air. In SAE Technical Paper Series, vol. 1 (2018).

[14] Bardis, K., Xu, G., Kyrtatos, P., Wright, Y. M. \& Boulouchos, K. A Zero Dimensional Turbulence and Heat Transfer Phenomenological Model for PreChamber Gas Engines. SAE Technical Papers 2018April, 1-28 (2018).

[15] Xu, G., Wright, Y. M., Schiliro, M. \& Boulouchos, K. Characterization of combustion in a gas engine ignited using a small un-scavenged pre-chamber (2018).

[16] Thelen, B. C. \& Toulson, E. A Computational Study of the Effects of Spark Location on the Performance of a Turbulent Jet Ignition System. SAE Technical Paper (2016).

[17] Gholamisheeri, M., Thelen, B. C., Gentz, G. R., Wichman, I. S. \& Toulson, E. Rapid compression machine study of a premixed, variable inlet density and flow rate, confined turbulent jet. Combustion and Flame 169, 321-332 (2016).

[18] Gholamisheeri, M., Wichman, I. S. \& Toulson, E. A study of the turbulent jet flow field in a methane fueled turbulent jet ignition (TJI) system. Combustion and Flame 183, 194-206 (2017).

[19] Gussak, L. A., Karpov, V. P. \& Tikhonov, Y. V. The Application of Lag-Process in Prechamber Engines. In SAE Technical Paper Series, vol. 1 (1979).

[20] Andersson, Ö. et al. High Speed Combustion Imaging in a Large Bore Gas Engine: The Relationship Between Pre- and Main Chamber Heat Release. In Volume 8A: Heat Transfer and Thermal Engineering, V08AT09A022 (ASME, 2014).

[21] Heywood, J. B. Internal Combustion Engine Fundementals (1998).

[22] Woschni, G. A Universally Applicable Equation for the Instantaneous Heat Transfer Coefficient in the Internal Combustion Engine. In SAE Technical Paper Series, vol. 1 (1967)

[23] Gussak, L. A. The Role of Chemical Activity and Turbulence Intensity in Prechamber-Torch Organization of Combustion of a Stationary Flow of a FuelAir Mixture. In SAE Technical Paper Series, vol. 1 (1983).

[24] Shah, A. Improving the Efficiency of Gas Engines using Pre-chamber Ignition. Ph.D. thesis (2015). 


\section{CONTACT INFORMATION}

Ponnya Hlaing

PhD Student

Clean Combustion Research Center (CCRC)

Internal Combustion Engine Lab

King Abdullah University of Science and Technology (KAUST)

Thuwal, Saudi Arabia

ponnya.hlaing@kaust.edu.sa

Phone no: +966 565485657

\section{ACKNOWLEDGEMENTS}

The paper is based upon work supported by Saudi Aramco Research and Development Center FUELCOM 3 program under Master Research Agreement Number 6600024505/01. FUELCOM (Fuel Combustion for Advanced Engines), is a collaborative research undertaking between Saudi Aramco and KAUST intended to address the fundamental aspects of hydrocarbon fuel combustion in engines, and develop fuel/engine design tools suitable for advance combustion modes. The author would like to thank King Abdullah University of Science and Technology (KAUST) and the Clean Combustion Research Center (CCRC) for lab facilities and research support. Last but not least, the authors would like to convey gratitude towards the IC Engine Lab Safety Supervisor Adrian I. Ichim and the lab technician Riyad H. Jambi for their kind input and assistance in performing the experiments.

\section{DEFINITION/ABBREVIATIONS}

$\begin{array}{ll}\text { BDC } & \text { Bottom dead center } \\ \text { CAD } & \text { Crank angle degree } \\ \text { CFD } & \text { Computational fluid dynamics } \\ \text { CO } & \text { Carbon monoxide } \\ \text { CoV of IMEPg } & \text { Covariance of gross IMEP } \\ \text { IMEP } & \text { Indicated mean effective pressure } \\ \text { MC } & \text { Main combustion chamber } \\ \text { PC } & \text { Pre-chamber } \\ \text { PCSI } & \text { Pre-chamber spark ignition } \\ \text { THC } & \text { Total unburned hydrocarbons } \\ \text { TPA } & \text { Three pressure analysis }\end{array}$

